\title{
VARIACIONES SOBRE LAS DERIVACIONES JURISPRUDENCIALES A PARTIR DEL INCISO FINAL DE LA DA 20. ${ }^{\text {ET }}$
}

\author{
Mariano Treviño Pascual \\ Profesor Ayudante de Derecho del Trabajo y de la Seguridad Social \\ Universidad de Zaragoza
}

DOI: $10.1387 /$ lan-harremanak.15401

\section{ABSTRACT}

La Sala de lo Social del Tribunal Supremo introdujó un importante matiz en su primera doctrina, para establecer que "la contratación laboral en la Administración Pública al margen de un sistema adecuado de ponderación de mérito y capacidad impide equiparar (a quienes se encuentran en esa situación) a trabajadores fijos de plantilla». Eso quiere decir que aunque el trabajador con contrato temporal al que se le prolongue la relación de empleo se considere con "contrato indefinido", no consolida la situación de "fijeza», que sólo puede alcanzarse mediante los correspondientes procedimientos selectivos. La Sala de lo Social del Tribunal Supremo, -entre julio de 2013 y junio de 2014 - ha admitido, en el ámbito de la relación laboral en el empleo público, la estrecha relación que existe entre la extinción contractual por amortización de la plaza y la extinción de los contratos de trabajo de carácter temporal por agotamiento del plazo de vigencia, aunque consideraba innecesario acudir a los procedimientos de extinción colectiva o individual por causas objetivas previstos en los artículos 51 y 52.c) del ET. Y en recientes pronunciamientos el TS ha matizado su posición tradicional, que ha dado lugar a un nuevo avance motivado por la entrada en vigor de la disposición adicional vigésima del ET con relación al personal laboral de las Administraciones públicas, a quien a partir de ahora se aplica lo dispuesto en los artículos 51 y 52.c) del ET. Pues, como señala «el último párrafo de esta Adicional al dar prioridad de permanencia al personal fijo 
evidencia que la misma se aplica, también, al personal indefinido no fijo y al interino por vacante».

Palabras clave: Igualdad de acceso al empleo público, estabilidad en el empleo, trabajadores fijos, trabajadores indefinidos no fijos y trabajadores interinos por vacante.

The Social Chamber of the Supreme Court introduced an important nuance in his first doctrine to establish that "the hiring in Public Administration outside an appropriate weighting system prevents equate merit and ability (to those in that situation) to fixed permanent employees». That means that even if the worker a temporary contract that will extend the employment relationship is deemed to "longterm contract» does not consolidate the status of "fixity" which can only be achieved through the appropriate selection procedures. The Social Chamber of the Supreme Court, among July 2013 and June 2014, has admitted in the field of employment in public employment, the close relationship between the contractual termination of amortization of the job position and the termination of employment contracts by temporary expiry of the period of validity, although considered unnecessary recourse to methods of collective or individual extinction for objective reasons provided for in Articles 51 and 52 c) of the ET (General agreement workers). And in recent statements the TS (Supreme Court) has changed its traditional position, which has resulted in a new progress motivated by the entry into force of the twentieth additional disposal of ET in relation to the workforce of the public authorities, who advance from now apply the dispositions of Articles 51 and 52 c) of the ET. Well, as "the last paragraph of this Extra to give priority to permanent staff spent evidence that it is also applied to not fixed long-term workers and interim staff for a vacant» he says.

Key Words: Equal access to public employment, job security, regular employees and not fixed long-term workers and temporary workers for vacant. 


\section{Principios constitucionales que infoman el régimen jurídico del personal laboral de las Administraciones Públicas}

Por imperativo de lo dispuesto en el artículo 7 del Estatuto Básico del Empleado Público (EBEP), aprobado por la Ley 7/2007, de 12 de abril, el personal laboral al servicio de las Administraciones Públicas se rige de acuerdo a lo establecido en la Legislación laboral, y por los preceptos del EBEP que así lo dispongan.

Con semejante premisa de partida y a priori sería de aplicación a los entes públicos el artículo 15.3 ET el cual viene a establecer como presunción la consideración de indefinidos de cuantos vínculos de duración determinada hayan sido celebrados en fraude de ley, tras la pérdida del carácter temporal del trabajo y su conversión en permanente, bien por finalización del contrato temporal o bien porque dejó de serlo porque nunca lo fue, por realizar siempre labores permanentes, normales y constantes de la Administración Pública y quedar desnaturalizada la relación temporal desde entonces. Hay que recordar que rige el principio de que las necesidades permanentes - a la actividad normal, habitual y continuada - ha de proveerse con personal fijo, esto es, con trabajadores contratados por tiempo indefinido, regla aplicable incluso si el trabajo permanente o normal surge después de la celebración del contrato durante su ejecución (Alonso Olea y Casas Baamonde, 1993); tampoco se debe olvidar, que jurisprudencia reiterada y firme, sin duda ni contradicción, declaró que los pactos por los cuales se van sucediendo respecto de un mismo trabajador, sin solución de continuidad, contratos "encadenados» (contratos sucesivos) por tiempo cierto sin razón suficiente con la finalidad de poder despedir libremente, constituye un verdadero fraude de ley o un claro abuso de derecho. En suma, un acto realizado al amparo del texto de una norma (artículo 15.1 ET) persiguiendo un resultado prohibido por el ordenamiento jurídico (el atentado a la estabilidad en el empleo), cuya consecuencia conforme al artículo 6.4 CC, es «la aplicación de la norma que se hubiera tratado de eludir», en este caso el artículo 15.3 ET (Alonso Olea y Casas Baamonde, 2005). Por lo que, al emerger el fraude de ley en la contratación entre partes, se acudiría a las figuras legalmente amparadas en los artículos 49.1.l) y 51 o 52 del Estatuto de los Trabajadores, cuando no se haya realizado la contratación laboral con sujeción a contenido presupuestario, por ausencia o insuficiencia de presupuesto. 
Sin embargo, semejante solución parecería que pugna con otros principios constitucionalmente aplicables a los poderes públicos, en especial los de igualdad, mérito y capacidad (artículos 14, 23.2 y $103.3 \mathrm{CE}$ ) en el acceso al empleo público, cuyo desarrollo encuentra amparo en el artículo 55 EBEP de conformidad con el cual además de los citados resulta necesario tener en cuenta en la selección de personal una amplia panoplia de principios.

Por ello, hay quien piensa que el problema apuntado coloca al intérprete ante dos sectores del ordenamiento jurídico, cuyos principios inspiradores son diferentes, cuando no contradictorios: el laboral atiende a utilidades privadas, vinculadas fundamentalmente a la estabilidad en el empleo; en cambio, el administrativo pretende garantizar ciertos intereses generales, en especial la no discriminación en el ingreso a los puestos ofertados por el sector público. Y argumenta, que las instituciones concernidas en semejante concurrencia conflictiva no aparecen situadas en el mismo plano, pues una presenta carácter eminentemente ordinario y otra fundamentalmente constitucional, debiendo quedar sacrificada la primera frente a la segunda (Fernández, 2009).

Razonamiento del que discrepamos, pues integran el contenido del derecho al trabajo (artículo 35.1 CE) no sólo la libertad de trabajar, sino también el derecho a un puesto de trabajo que, en su vertiente individual, "se concreta en el igual derecho de todos a un determinado puesto de trabajo si se cumplen los requisitos necesarios de capacitación y en el derecho a la continuidad o estabilidad en el empleo, es decir, a no ser despedidos si no existe una justa causa» (SSTC 22/1981, de 2/Julio, FJ 8; 125/1994, de 25/Abril, FJ 3 ; y 192/2003, de 27/Octubre, FJ 4).

Por lo que, sin perjuicio de la distinta naturaleza jurídica de los contenidos de los preceptos reconocidos en la Sección 2. ${ }^{\mathrm{a}}$ y en la Sección $1 .^{\mathrm{a}}$, se debe reconocer el carácter fundamental al derecho al trabajo del artículo 35.1 CE, de modo que las características atribuidas a los derechos fundamentales han de valer también para este derecho. Este razonamiento se adapta más a la función y el significado que tiene el reconocimiento del derecho al trabajo (Baylos, 2004). Pues, junto a la vinculación general y a la aplicabilidad directa de los derechos y libertades reconocidos en el Capítulo II del Título I, son notas de los mismos la reserva de Ley y la indisponibilidad del legislador de su contenido esencial, de un lado; y, de otro, la tutela judicial a través del recurso de inconstitucionalidad de las leyes y de la tutela judicial ordinaria, características identificadoras de los derechos fundamentales son aplicables a todos los derechos regulados en el Capítulo II del Título I CE (Rivero Lamas, 2002).

Por todo ello, las exigencias constitucionales de igualdad, mérito y capacidad son de obligado cumplimiento para los poderes públicos a la hora de contratar personal a su servicio, ya sea funcionario o laboral, porque, si bien en este último caso actúa como una empresa, la Administración sigue siendo la misma 
cuando precisa a uno o a otro, pues incluso el propio artículo 35.1 CE establece «el igual derecho de todos a un determinado puesto de trabajo si se cumplen los requisitos necesarios de capacitación».

No debe olvidarse, por lo demás, que el derecho de acceso de todos los ciudadanos al empleo público en condiciones de igualdad, que ahora recuerda el artículo 55 del EBEP, es un derecho fundamental proclamado en la Constitución (artículos 14 y 23.2). También es importante porque dispone que los principios de igualdad, mérito y capacidad son aplicables tanto a la selección de personal funcionario como laboral fijo o temporal, en este sentido no debe olvidarse que el artículo 55.2 EBEP, no distingue entre personal laboral fijo y temporal (Vivero, 2009), por lo tanto, esa especialísima exigencia ya está homogeneizada para todos los empleados públicos sin distinción y, por lo tanto, no puede servir para justificar ningún trato diferencial entre unos y otros a efectos de estabilidad en el empleo.

Del contenido esencial del derecho fundamental de acceder en condiciones de igualdad al empleo público forman parte ineludiblemente los principios de mérito y capacidad y el contenido esencial del derecho fundamental en cuestión despliega su eficacia en la exigencia misma de convocatoria pública y de libre acceso a los puestos de trabajo vacantes, quedando prohibidas las convocatorias restringidas y de manera absoluta las conversiones automáticas.

No obstante, los principios constitucionales de mérito y capacidad no son absolutos y admiten, en consecuencia, su conjugación, que no eliminación, con otros principios o bienes constitucionalmente protegidos, sobre todo, como he apuntado, por el de estabilidad en el empleo. Contenido esencial del derecho constitucional a acceder en condiciones de igualdad al empleo público del que forman parte el principio de publicidad, junto a los de mérito y capacidad y a los de igualdad y no discriminación y que no alcanza solo al acceso al empleo, sino también al desarrollo, vicisitudes y extinción de las relaciones jurídicas de empleo, ya administrativas ya laborales (Vivero, 2009).

Si la Administración debe ser objetiva para servir al Gobierno, la objetividad (imparcialidad en el ejercicio de sus funciones, que se garantiza con la inamovilidad en el puesto de trabajo) implica la estabilidad en el empleo, que, por tanto, no sólo es una conquista social de los empleados públicos, sino también una exigencia para la prestación de los servicios públicos: la garantía de la objetividad de la Administración al servicio de los intereses generales. (López Gómez, 2009). En definitiva, la inamovilidad —entendida como estabilidad en el empleo- tiene más que ver con la permanencia y esencialidad del servicio público en cuestión que con la imparcialidad, en el ejercicio de la función pública, que — siendo el origen histórico de la inamovilidad de los funcionarios- debería hoy considerarse asegurada por las normas de un sistema democrático que garantiza los derechos fundamentales y libertades públicas de todos los ciudadanos 
y, por ende, de los empleados públicos, sea cual sea la naturaleza jurídica de su relación de prestación de servicios (Alarcón, 2015).

Pese a ello, se piensa que se concilia el principio de estabilidad, al que no es posible -en un sistema democrático- renunciar, puesto que está en juego el derecho al trabajo de miles de ciudadanos constitucionalmente reconocido con los de igualdad, mérito y capacidad en el acceso al empleo público cuando el contrato tiene una vocación de fijeza, lo que se compadece mal en el supuesto de que la convocatoria lo haya sido para ocupar un puesto temporal y no para ocupar un puesto de trabajo concebido, desde el principio, como ilimitado en el tiempo. Pues, en efecto, los procesos selectivos de personal laboral fijo son mucho más exigentes que los del personal temporal. Distinción razonable siempre y cuando los segundos no eliminen o desnaturalicen del todo los principios de mérito y capacidad (se trata de hacer compatibles la selección suficientemente objetiva, que respete el derecho constitucional a acceder en condiciones de igualdad al empleo público en régimen laboral, con la eficacia y rapidez de los procesos selectivos, de modo que se respete también el principio constitucional de eficacia de la actuación administrativa del artículo 103.1 CE). Esta circunstancia impide aplicar sin más la normativa laboral sobre la vis atractiva del contrato indefinido común, inequívocamente pensada para el sector privado, aplicación que contravendría el derecho constitucional a acceder en condiciones de igualdad al empleo público en régimen laboral. Añádase a lo anterior, que muchos ciudadanos titulares al derecho constitucional a acceder al empleo público en condiciones de igualdad concurrirían a los procesos selectivos para puestos de trabajo fijo y no, en cambio, para los temporales, al ser las circunstancias laborales bien diferentes, de modo que la conversión de los puestos convocados como temporales en fijos en virtud de la vis atractiva del contrato indefinido común contravendría frontalmente el citado derecho constitucional (Vivero, 2009).

Argumentos que pueden neutralizarse por aplicación del principio de seguridad jurídica, en la medida en que el principio de publicidad forma parte del derecho constitucional a acceder en condiciones de igualdad al empleo público y comprende la convocatoria pública abierta al público en general, a la ciudadanía; es decir, de libre acceso, y publicada de manera suficiente para que todos los aspirantes potenciales puedan tener oportuno conocimiento de la misma y adoptar las decisiones correspondientes, con conocimiento de todas las consecuencias que derivan de presentarse o no presentarse a los puestos de trabajo convocados con carácter temporal, entre ellas la de la posible consolidación en el empleo público consecuencia de irregularidades o fraude a ley en la contratación temporal.

Y por el hecho, que aún cuando la referencia a los principios de mérito y capacidad se suele realizar de manera conjunta, como si se tratase de un mismo concepto, parte de la doctrina se ha referido a la delimitación entre ambos tér- 
minos, «méritos» y "capacidades». Vinculando al segundo aquellos aspectos que se acreditan en pruebas teóricas o prácticas cuya finalidad perseguida es la de constatar los conocimientos y aptitudes de los aspirantes, lo que conlleva ineludiblemente la asociación del concepto de capacidad al sistema de selección basado en la "oposición». Mientras que, los méritos, englobaría aquellos aspectos que hacen referencia a las cualidades-habilidades adquiridas por los aspirantes durante su trayectoria profesional, cuya acreditación se lleva a cabo por medio del instrumento selectivo denominado "concurso" (Ramos, 2009), y es que ambos garantizan «el igual derecho de todos a un determinado puesto de trabajo si se cumplen los requisitos necesarios de capacitación».

El EBEP, aprobado por la Ley 7/2007, de 12 de abril, dio respaldo legislativo expreso a la figura jurisprudencial del «trabajador indefinido no fijo al servicio de las Administraciones Públicas», concretamente, su artículo 8.2 dispone que los empleados públicos se clasifican en: «d) Personal laboral, ya sea fijo, por tiempo indefinido o temporal» y el artículo 11.1 del propio Estatuto establece que: «es personal laboral el que en virtud de contrato de trabajo formalizado por escrito, en cualquiera de las modalidades de contratación de personal previstas en la legislación laboral, presta servicios retribuidos por las Administraciones Públicas. En función de la duración del contrato, éste podrá ser fijo, por tiempo indefinido o temporali. Se establece, definitivamente, la diferencia de trato legal entre empleados del sector público y el privado, respecto de la suerte que corre por el uso abusivo de la sucesión de contratos o relaciones de duración determinada, que ha sido considerada como perfectamente acomodada al ordenamiento comunitario, en particular, a la Directiva 1999/70/CE, de 28 de junio, habida cuenta esta disposición supranacional deja cierto margen de actuación a los diferentes Estados miembros a fin de transponer sus objetivos.

$\mathrm{El}$ artículo $15.3 \mathrm{ET}$, establece, que «se presumirán por tiempo indefinido los contrato temporales celebrados en fraude de ley", por lo se ha afirmado que el ET apenas aporta algo más a la hora de calificar el fraude de ley y que tras la reforma laboral de 2006 se establecen parámetros y límites claros legales a la utilización abusiva de contratos temporales (López Gandía, 2010), pese al hecho de que jurisprudencia reiterada e inconcusa sí hubiera establecido que contrato sucesivos de corta duración sin razón suficiente con la finalidad de despedir libremente es un caso claro de fraude en la contratación laboral como expusimos en el párrafo segundo de esta comunicación, incorporando alguna de las medidas contempladas por la Directiva 1999/70, al fijar una duración máxima total de los sucesivos contratos de trabajo de duración determinada y limitación del número de renovaciones.

Como son las del artículo 15.5 ET que introduce ciertos límites en orden a la utilización sucesiva de contratos temporales, configurando en la propia ley un supuesto de presunción iuris et de iure de necesidad estable y permanente o pre- 
sunción a favor de la fijeza. Se trata pues de una presunción iuris et de iure de utilización indebida de la contratación temporal sucesiva con el mismo trabajador o de «favor» hacia la contratación indefinida.

Se podría considerar perfectamente inútiles y una auténtica regresión de los derechos de los trabajadores tanto el artículo 15.5 ET como su Disposición Adicional 15. a , pues se podía considerar plenamente vigente y compatible con la Directiva 1999/70 la doctrina sobre los casos más claros de fraude señalada en el párrafo segundo de la presente comunicación, porque la cláusula 5 de la citada Directiva que autoriza «introducir para prevenir los abusos por la utilización sucesiva de contratos o relaciones laborales de duración determinada a los Estados miembros..., cuando no existan medidas legales equivalentes para prevenir los abusos». Y en España ya existía el fraude a ley en el contratación temporal y toda su doctrina jurisprudencial que determinaba en qué condiciones los contratos de trabajo o relaciones laborales de duración determinada: a) se considerarán «sucesivos» (pues la jurisprudencia partía del criterio de unidad del vínculo aunque entre un contrato y otros hayan transcurrido períodos superiores a 20 días de caducidad para reclamar por despido, supuestos en que se entiende que ha habido un solo contrato de carácter indefinido, incluso aunque se hayan producido interrupciones, o se hayan combinado con contratos administrativos, aunque estos sean últimos, siendo competente la jurisdicción social); b) se considerarán celebrados por tiempo indefinido, por lo que, desde un primer momento, se consideró plenamente aplicable al sector público la presunción a favor del carácter indefinido de la relación laboral, sin que con ello se viesen afectados los principios que rigen el acceso al empleo público.

\section{Trabajador fijo, trabajador indefinido no fijo, trabajador interino por vacante en las Administraciones Públicas: las contradicciones de la contratación laboral}

La aplicación del artículo 15.3 ET era consecuencia del respeto de los principios de legalidad y seguridad jurídica contenidos en el artículo 9.3 CE y también del principio de estabilidad en el empleo, constitucionalmente reconocido en el artículo 35.1 CE. Y, así, el Tribunal Supremo, establecía que la primacía absoluta corresponde a la legalidad laboral, a la vis atractiva del contrato indefinido común, conforme al artículo $15.3 \mathrm{ET}$ y a otros preceptos más. En efecto, el artículo 15.3 ET prescribe que «se entenderán por tiempo indefinido los contratos celebrados en fraude de ley", de manera que un contrato temporal celebrado incumpliendo las condiciones legales tiene esa consecuencia en detrimento del empresario. Tratándose de la Administración Pública consideró tan aplicable esta regla, como en la empresa privada. Se estimaba que la Administración Pú- 
blica está sujeta al artículo 15 ET, y por ello debe declararse la fijeza del trabajador contratado sucesivamente (SSTS de 6/5/1992 (RCUD 1600/1991).

De manera, que constatada una irregular contratación temporal la sanción que corresponde es la misma que si se tratase de empresarios privados, esto es, la conversión del contrato temporal en indefinido común, y en caso de cese sin causa la calificación de improcedencia o nulidad con las consecuencia oportunas, incluida, en su caso, la readmisión. Para esta jurisprudencia, la primacía absoluta corresponde a la legalidad laboral, a la vis atractiva del contrato indefinido común, conforme al artículo 15.3 ET y a otros preceptos más.

Por SSTS de 20 y 21/1/1998 (RCUD. 317 y 315/1997), se destaca que «el alcance de esta posición ha sido de nuevo matizado a partir de la sentencia de 7 de octubre de 1996, en la que se establece que "la contratación en la Administración pública al margen de un sistema adecuado de ponderación de mérito y capacidad impide equiparar a los demandantes a trabajadores fijos de plantilla, condición ligada a la contratación por el procedimiento reglamentario, sin perjuicio de su contratación, en su caso, como trabajadores vinculados por un contrato de trabajo por tiempo indefinido». Por lo que, al final la Sala de lo Social del Tribunal Supremo introdujo un importante matiz en su doctrina, para establecer que "la contratación laboral en la Administración Pública al margen de un sistema adecuado de ponderación de mérito y capacidad impide equiparar (a quienes se encuentran en esa situación) a trabajadores fijos de plantilla». Eso quiere decir que aunque el trabajador con contrato temporal al que se le prolongue la relación de empleo se considere con "contrato indefinido", no consolida la situación de «fijeza», que sólo puede alcanzarse mediante los correspondientes procedimientos selectivos. Por tanto, la Administración está obligada a proveer ese puesto de trabajo de manera regular y, una vez producida tal provisión, existirá causa lícita para extinguir aquel contrato. Además de modo reiterado, la jurisprudencia venía manteniendo que la extinción del contrato de trabajo en estos casos no confiere al afectado derecho a indemnización, con olvido del carácter temporal de la contratación y de las exigencias de la Directiva 1999/70/CE, de 28 de junio, por ser su situación comparable a la de un funcionario interino (Sánchez Morón, 2011).

La doctrina, que validaba el cese acordado por una Administración Pública con respecto a la extinción del contrato de interinidad por vacante SSTS 14/3/2002 (RCUD 3191/2001), se extendió al contratado indefinido. El Pleno de la Sala (STS 27/5/2002 (RCUD 2591/2001) argumenta que "el pacto de los contratos de interinidad en los que se conviene la prestación de servicios hasta que la plaza sea provista en propiedad, ha de entenderse sujeto a la condición subyacente de la pervivencia del puesto de trabajo. Conclusión que responde a la propia naturaleza de la relación contractual de interinidad, referida al desempeño con carácter de provisionalidad de un puesto de trabajo. Entenderlo de otro modo llevaría 
a conclusiones absurdas ya que supondría la transformación del hecho de la interinidad en una situación propia de un contrato indefinido — pues el cese del interino solo se produce por la incorporación del titular, lo que en principio no procede al suprimirse la plaza-, o bien significaria la vinculación de la Administración a proveer una plaza que estima innecesaria, puesto que la ha suprimido. Por ello ha de entenderse que los contratos de interinidad no limita ni elimina las facultades de la Administración sobre modificación y supresión de puestos de trabajo, y que la supresión de la plaza es causa justa de la finalización del contrato temporal de interini$d a d »$. Esto es, la norma no prohíbe la amortización de vacantes, ni recorta la potestad organizativa de la administración y su autonomía para crear y suprimir puestos de trabajo.

Sin sacar todas las consecuencias de que la interinidad es en sí misma temporal, uno de los supuestos de la contratación temporal previstos en el artículo $15 \mathrm{ET}$, se piensa que la extensión del régimen extintivo del contrato de interinidad por vacante al contratado indefinido estaría creando una situación a medio camino entre la indefinición contractual, que es consecuencia del artículo 15.1 y 15.3 ET, y la contratación temporal, tolerada por el citado artículo 15, algo que no está contemplado como posible en la Ley (Nicolás Bernad, 2009), afirmación que resulta sorprendente a la vista del respaldo legislativo expreso a la figura jurisprudencial del «trabajador indefinido no fijo al servicio de las Administraciones Públicas» dado por el EBEP, por lo que la incorporación de la referencia a los indefinidos en el EBEP ha tenido por objeto recoger la figura del indefinido no fijo delimitada por la jurisprudencia, y crear con carácter general un "tertium genus» entre fijos o temporales y es que aunque el carácter indefinido del contrato implica desde una perspectiva temporal que éste no está sometido, directa o indirectamente a un término señalado o conocido, palabra polisémica — que significa, a la vez, temporal e indefinido—, pero desde la aparición del Derecho del Trabajo es sinónimo de permanencia no temporal en el puesto de trabajo, pese a ello la STS de 23/7/2013 (RCUD 1380/2012) establece que «esto no supone que el trabajador consolide, sin superar los procedimientos de selección, una condición de fijeza en plantilla que no sería compatible con las normas legales sobre selección de personal fijo en las Administraciones Públicas. De ahi que, aunque se declare contraria a Derecho la causa de temporalidad pactada, conforme al art. 49.1.c) del ET, y se reconozca la relación como indefinida, ésta queda sometida a una condición - la provisión de la vacante por los procedimientos legales de cobertura-, cuyo cumplimiento determina la extinción del contrato de trabajo mediante la correspondiente denuncia del empleador público, sin que sea preciso recurrir a las modalidades de despido que contemplan los arts. 51 y 52 del ET».

A diferencia de los supuestos previstos en el artículo 49.1.c) ET, el carácter indefinido del contrato implica desde una perspectiva temporal que éste no puede estar sometido, directa o indirectamente, a un término, salvo anular todo sentido a esa cualidad que se anuda de contrato indefinido. Por supuesto, esto 
no supone que el trabajador consolide, una condición de fijeza en plantilla, sin superar los procedimientos de selección, pero sí que la extinción de sus contratos por causas objetivas - amortización — no puede producirse al margen de los procedimientos legalmente establecidos a tal fin y con el abono de las correspondientes indemnizaciones para el caso de resultar justificada la extinción (Molina, 2014).

Consiguientemente, las disposiciones del EBEP son aplicables al trabajador indefinido no fijo, poniendo de manifiesto la existencia de sustanciales diferencias entre el contrato laboral indefinido no fijo de las Administraciones Públicas y el contrato de interinidad por vacante. El contrato de interinidad por vacante se encuentra hoy regulado en el artículo 4 del Real Decreto 2720/1998 - en donde únicamente se hace referencia a la interinidad para sustituir a trabajadores con derecho a reserva de puesto de trabajo, si bien, al amparo de la Ley 14/1994 que, en el Real Decreto 2546/1994 se produjo su admisión para todas las Administraciones Públicas-, y se circunscribe a la cobertura temporal de un puesto de trabajo durante el proceso de selección o promoción para su cobertura definitiva y está sujeto a la exigencia de identificación del puesto de trabajo cuya cobertura definitiva se ha de producir mediante el proceso de selección o promoción coincidiendo su duración, en el caso de las Administraciones Públicas, el proceso de selección o promoción, según la normativa correspondiente en cada caso. De modo que la identificación del puesto de trabajo actúa de requisito esencial en esta modalidad contractual temporal, y la cobertura provisional de la vacante y no otro es el dato fundamental para calificar la relación jurídica como contrato de interinidad, por vacante, bastando con que la identificación de la plaza que se contrata se realice de modo que la actitud posterior de la Administración no ocasione indefensión al afectado y que el acto empresarial se realice con criterios objetivos.

La figura del indefinido no fijo viene planteando grandes problemas de interpretación en los supuestos en los que estos trabajadores no ocupan una plaza prevista en el elenco de puestos de trabajo que configuran la plantilla o RPT de la entidad pública. Esto es lo que ocurre con trabajadores falsamente contratados como temporales cuando en realidad van a atender requerimientos permanentes de la Administración Pública o cuando se supera la duración máxima temporal prevista en la legislación laboral para ciertos contratos de duración temporal (pues no hay obligación de incluir en la relación de puestos de trabajo los puestos ocupados por trabajadores temporales) o aquellos provenientes del reconocimiento de una relación laboral bajo la forma de falso autónomo, pues el EBEP tampoco consigue hacer desaparecer el contrato administrativo de prestación de servicios, que mantiene la Ley de Contratos del Sector Público (Ley 30/2007, de 30 de octubre, y su posterior y vigente texto refundido aprobado por Real Decreto Legislativo 3/2011, de 14 de noviembre). Figura del "contrato de servicios» cuyo sujeto, aparte de la Administración Pública con- 
tratante, puede ser no solamente una sociedad o empresa sino también una persona física, en cuyo caso, de nuevo, una relación jurídica materialmente laboral aparece regulada como contrato administrativo en un texto normativo posterior al EBEP (que obviamente tampoco se incluirán en la correspondiente RPT) (Selma, 2014).

Y aunque el "contrato de interinidad por vacante», sin duda, presenta una grandísima identidad con el contrato del trabajador «indefinido no fijo» cuando el objeto de éste consiste en atender requerimientos propios de un puesto de trabajo previamente catalogado en la RPT, la cercanía ya no es tan estrecha con el contrato «indefinido no fijo» cuando se utiliza para ocupar un puesto de trabajo expresamente creado para el indefinido no fijo, sin reflejo en la RPT de la entidad (lo que pasa casi siempre).

El contrato de interinidad por vacante se encuentra previsto para una finalidad concreta, la atención provisional de los servicios durante el periodo de tiempo necesario para que se convoquen y cubran puestos de forma definitiva mediante los correspondientes procedimientos, siendo inaceptable que, bajo pretexto de la utilización de esta modalidad contractual, se prolongue la situación de provisionalidad indefinidamente en el tiempo, más allá del razonablemente exigible para poner en marcha los mecanismos para la cobertura definitiva del puesto. Por ello, si se utiliza la contratación interina para someter a los trabajadores a un resultado no querido por la Ley, esto es ante una situación de inestabilidad en el empleo injustificada, nos encontraríamos ante el fraude de Ley (López Gómez, 2009).

Y como se venía considerando que la relación laboral de los indefinidos no fijos - al igual que la de los laborales interinos por vacante-; puede extinguirse tanto por cubrirse reglamentariamente como por la amortización o supresión de dicha plaza, en cuyo caso ya no puede cubrirse reglamentariamente; sin necesidad de acudir al procedimiento del despido colectivo del artículo $51 \mathrm{ET}$ o, en su caso, al del despido objetivo del artículo 52.c) y 53 ET. En la Sentencia de Sala General de 22/7/2013 (RCUD 1380/2012), siguiendo con alguna matización la doctrina anterior de la propia Sala y a la que por razones de seguridad jurídica tiene que atenerse para que la condición resolutoria pueda operar precisa de un hecho futuro e incierto no dependiente de la voluntad de una de las partes - artículo $1115 \mathrm{CC}$ - Y Y aunque es manifiesto que la amortización de la plaza es un hecho incierto, que depende de la estricta decisión del empleador público, único que tiene el control de que acaezca o no la condición extintiva, la amortización, amparada en la potestad de auto-organización era causa de extinción de los contratos indefinidos no fijos y de los contratos de interinidad por vacante y daba lugar a una forma particular de cumplimiento de la condición resolutoria inherente al contrato, y por lo tanto, generaban la extinción del contrato de trabajo sin derecho del trabajador afectado a obtener indemnización alguna derivada de 
su cese (49.1.b ET). Posteriormente —en realidad entre julio de 2013 y junio de 2014-, se pasó a admitir la estrecha relación que existe entre esta forma de extinción contractual y la extinción de los contratos de trabajo de carácter temporal por agotamiento del plazo de vigencia, lo que llevó a nuestros tribunales a reconocer a estos trabajadores la indemnización prevista para estas situaciones en el artículo 49.1.c) ET y otorgar al trabajador indefinido no fijo que ha sido objeto de un despido procedente la misma indemnización por fin de contrato establecida para la mayoría de los contratos temporales en dicho precepto. Dado que la naturaleza del vínculo contractual conduce a aceptar la amortización como causa válida de terminación de un contrato de duración incierta y pese a la asimilación a efectos extintivos entre la relación «indefinida no fija» y la interinidad, es la interpretación que se impone con mayor fuerza si se atiende a la Directiva 1999/70/ CE y a la jurisprudencia que la interpreta. Así las (STS de 14/10/2013 (RCUD 68/2013 ) y, en idéntico sentido, la STS de 25/11/2013 (RCUD 771/2013), STS 21/1/2014 (RCUD 1086/2013) y STS $11 / 2 / 2014$ (RCUD 1278/2013)).

Con la reciente STS 24/6/2014 (RC 217/2013), cuya doctrina es reiterada por las SSTS (Social) 14/7/2014(RCUD. 1807/2013 y 2052/2013), se ha producido un nuevo avance en esta respuesta, al establecer, en relación con los contratos de interinidad por vacante, que nos encontramos ante un contrato temporal de duración indeterminada, pero en el que consta que el término pactado llegará: cuando la vacante ocupada se cubra tras finalizar el proceso de selección que se convocará para cubrirla. Por tanto, la idea de que la amortización extingue el contrato porque el mismo tiene una condición resolutoria implícita debe rechazarse, ya que nos encontramos ante una obligación a término indeterminado y no ante una condición. Sin embargo, en este caso asistimos a un acto de la empleadora que supone la extinción de un contrato temporal antes de que llegue su vencimiento, lo que supone un perjuicio para la parte trabajadora que ve truncadas sus expectativas de empleo, incluso de ganar en concurso la plaza que ocupa.

Sorprende que el Tribunal Supremo haya tardado tanto tiempo en percatarse que el contrato temporal de interinidad no es un contrato sometido a condición resolutoria, pues tal afirmación se corresponde con lo establecido en el artículo 4 Real Decreto 2720/1998, porque a partir del Real Decreto 2546/1994, la voluntad de la norma es clara en el sentido de establecer un límite a la duración del contrato de interinidad por vacante, esto es, «el tiempo que duren" los procesos selectivos, "conforme a lo previsto en su normativa especifica» (art. 4.2.b Real Decreto 2720/1998), que se refuerza con el art. 8.1.c). 4 del Real Decreto 2720/1998, al indicar expresamente como causa de extinción del mismo "el transcurso ... del plazo que resulte de aplicación en los procesos de selección en las Administraciones Públicas». Al ser un contrato sometido a término no existe verdadera incertidumbre respecto a la realización de la condi- 
ción aunque sí la hay respecto al cuándo. De ahí que la cobertura reglamentaria de la plaza perfectamente identificada que ocupa el interino por vacante no es sino el cumplimiento de un término certus an, incertus quando, lo que, como es lógico, determina automáticamente la extinción de ese contrato (o su novación, si es el propio interino quien obtiene la plaza), puesto que actúa como causa de temporalidad.

El mero transcurso del plazo aludido en dicha disposición, según Nicolás Bernad, cualquiera que este sea, no produce, en principio, el efecto pretendido de transformar la relación contractual de interinidad en contrato por tiempo indefinido, sino el efecto contrario de facultar al empleador para dar por terminada la relación contractual con el trabajador interino (Nicolás Bernad, 2002). Ahora bien, esta postura no deja clara la naturaleza jurídica del contrato de interinidad, porque la consecuencia del incumplimiento del término o la condición resolutoria es la conversión del contrato en indefinido y, producida la causa de extinción del contrato de interinidad, el incumplimiento de la obligación de denuncia expresa por una de las partes, tiene por efecto la prorroga del contrato por tiempo indefinido, salvo prueba en contrario que acredite la naturaleza temporal de la prestación (artículo 8.2 Real Decreto 2720/1998).

La Sentencia de 23/7/2013 (RCUD 1380/2012) que invoca una técnica civilista la condición resolutoria ex artículo 1117 CC y artículo 49.1.b) ET que potencia la discrecionalidad extintiva (tanto por la cobertura de la plaza, como por la amortización de la misma y equiparando la extinción de la interinidad por vacante con la extinción indefinido no fijo), salvo las indicaciones al respecto de la legislación administrativa a tal fin, que deja no obstante un gran poder de auto-organización, y sin indemnización (Molina, 2014). Y lo hace, no sobre la coherencia de las normas administrativas, que en última instancia no hacen sino salvaguardar una potestad de auto-organización administrativa, esto es, el poder de organización del empleador público al margen de las reglas comunes fijadas en el ET, sino sobre la invocación de la lógica civilista de las "condiciones resolutorias», inadecuadamente conforme al artículo 1117 CC y su proyección en el artículo 49.1.b ET. Por tanto, a las extinciones en el empleo público por motivos de orden económico y organizativo, se les exime del procedimiento y, por tanto de la indemnización. Esto supone seguir una lógica de estricta eficacia de la gestión administrativa al margen de cualquier otra consideración de derechos de los trabajadores, pese a su amparo constitucional, mutando en favor de la potestad de auto-organización.

Pues, como muy bien dice Alarcón Caracuel, la invocación del artículo 1117 del Código civil tiene sentido en relación con las condiciones suspensivas pero no con las resolutorias. En efecto, si el cumplimiento de una condición deviene imposible, es obvio que la relación jurídica sometida a una condición suspensiva se extinguirá, esto es, no nacerán las obligaciones pactadas por las partes. Por el 
contrario, cuando la relación jurídica está sometida a una condición resolutoria, dichas obligaciones ya han nacido y se están cumpliendo, y, es claro que, desaparecida la incertidumbre que pendía sobre ella al devenir imposible el cumplimiento de dicha condición resolutoria, la relación jurídica en cuestión se consolida, no se extingue (Alarcón, 2015).

Es evidente que este tipo contractual ha pasado de estar sujeto a condición a ser un contrato sometido a término, pero se debe advertir que se mantiene la expectativa de consolidación para el interino porque el contrato de interinidad por vacante habia superado el limite temporal máximo de tres años para su cobertura desde que quedó desierta, por lo que, de conformidad con los arts. 70.1 de la Ley 7/2007 (EBEP) y art. 4.2.b) del RD 2720/1998, la relación de la demandante se habia convertido en indefinida no fija,..." (STS de 14/7/2014 (RCUD 1807/2013) y 15/7/2014 (RCUD 1833/2013)).

Y como muy bien señala y resume la STS 14/7/2014 (RCUD. 2052/2013): «3. ... se ha rectificado el criterio precedente y se ha mantenido: a) que los contratos de interinidad por vacante están sujetos al cumplimiento del término pactado (la cobertura reglamentaria de la plaza) y que consiguientemente estamos ante una obligación a término y no ante una condición resolutoria, porque las obligaciones condicionales (arts. 1113 y sigs. CC) son aquellas cuya eficacia depende de la realización $o$ no de un hecho futuro e incierto, en tanto que en las obligaciones a término se sabe que el plazo necesariamente llegará, en forma determinada (se conoce que llegará y cuando ello tendrá lugar) o indeterminada (se cumplirá, pero se desconoce el momento). b) En la interinidad por vacante estamos en presencia de un contrato a término, siquiera indeterminado, que es el momento en que la vacante necesariamente se cubra tras finalizar el correspondiente proceso de selección; c) La amortización de la plaza por nueva RPT — permitida por el art. 74 EBEP_, no puede suponer la automática extinción del contrato de interinidad, pues no está prevista como tal, sino que requiere seguir previamente los trámites de los arts. 51 y $52 \mathrm{ET}$, aplicables al personal laboral de las Administraciones Públicas (arts. 7 y 11 EBEP), y en los que la nueva RPT ha de tener indudable valor probatorio para acreditar la concurrencia de la correspondiente causa extintiva. d) La doctrina es aplicable igualmente a los trabajadores indefinidos no fijos, cuya extinción contractual está igualmente sujeta a la cobertura de la plaza y —en su caso-a la amortización.

En conclusión, a partir de la STS 24/6/2014 (RC 217/2013), cuya doctrina es reiterada por las SSTS (Social) 14/7/2014 (RCUD. 1807/2013 y 2052/2013), —y por varias más — se ha puesto fin a una doctrina errónea, injusta y que ha producido en los últimos tiempos un perjuicio social grave: un indeterminado — pero no pequeño — número de trabajadores de las Administraciones Públicas españolas han perdido su trabajo -en ocasiones tras muchos años de servicio- por causas a ellos no imputables y sin haber percibido indemnización alguna. 


\section{Medidas adoptadas para la reparación o tutela por extinción del contrato del trabajador indefinido no fijo en las Administraciones Públicas}

El Tribunal Supremo distingue por primera vez, los supuestos en los que el contrato de trabajo de un interino por vacante y de un indefinido no fijo se extingue por amortización de la plaza de aquellos en los que su finalización viene provocada por la cobertura definitiva de la plaza, y ofrece un tratamiento jurídico diferente para ambos casos. Desecha para ambas causas de extinción el criterio del cumplimiento de la condición resolutoria y pasa a apoyar la extinción contractual en otras causas legalmente previstas en nuestro ordenamiento jurídico. Considera que mientras la celebración del correspondiente concurso puede considerarse como una forma de extinción de lo que en realidad es un contrato temporal sometido a un término incierto (certus an, incertus quando), no pude decirse lo mismo de la extinción de los contratos de trabajo por amortización de la plaza. Y es que, para estos casos, entiende que la introducción de la DA 20. ${ }^{a}$ ET implica necesariamente un cambio normativo que corrige el criterio anteriormente seguido (Selma, 2014).

De manera que, rectifica la doctrina que tradicionalmente había emanado de esa misma Sala que había mantenido que los contratos de interinidad por vacante y los del personal indefinido no fijo al servicio de las Administraciones públicas se extinguían no solo al cubrirse la plaza ocupada por el trabajador, como resultado del proceso ordinario de cobertura, sino también por la amortización de la plaza vacante ocupada, supuesto en el que la causa extintiva operaba directamente sobre el contrato, lo que hacía innecesario acudir a los procedimientos de extinción colectiva o individual por causas objetivas previstos en los artículos 51 y 52 c) del ET. Esta modificación que atañe a una reiterada doctrina de ese tribunal viene motivada por la entrada en vigor de la DA. ${ }^{a}$ ET tras la reforma laboral de 2012, pues mejora lo dispuesto en la Directiva Comunitaria 1998/59/CE, de 20 de julio, con relación al personal laboral de las Administraciones públicas, a quien a partir de ahora se aplica lo dispuesto en los artículos 51 y 52.c) del ET en los despidos colectivos por causas económicas, técnicas, organizativas o de producción y en los despidos por causas objetivas. En síntesis, tal y como señala literalmente el apartado 3 del fundamento jurídico tercero STS 24/6/2014 (RC 217/2013), "el último párrafo de esta Adicional al dar prioridad de permanencia al personal fijo evidencia que la misma se aplica, también, al personal indefinido no fijo y al interino por vacante» (Vela, 2014).

Asimismo, hay que volver a recordar, que cualquier duda sobre la aplicación al personal laboral de las Administraciones Públicas —incluidos los trabajadores indefinidos no fijos y los interinos por vacante-, de los artículos 51 y 52 del Estatuto de los Trabajadores ha quedado despejada con las reformas labora- 
les del año 2012, que adicionan una DA 20. ${ }^{\text {a }}$ al ET sobre la aplicación del despido por causas económicas, técnicas, organizativas o de producción en el Sector Público, delimitando su ámbito, con una descripción específica de las causas y con prioridades de permanencia de determinado personal laboral fijo, haciendo expresa referencia, en su inciso final a que: "Tendrá prioridad de permanencia el personal laboral que hubiera adquirido esta condición, de acuerdo con los principios de igualdad, mérito y capacidad, a través de un procedimiento selectivo de ingreso convocado al efecto, cuando asi lo establezcan los entes, organismos y entidades a que se refiere el párrafo anterior». Prácticamente en idénticos términos establece esta prioridad el artículo 41 del Real Decreto 1843/2012, prioridad que, en la forma expuesta, solamente tiene sentido interpretando que los primeros afectados por el despido objetivo o colectivo han de ser, precisamente, los trabajadores indefinidos no fijos.

En relación con esta preferencia no debe olvidarse, por lo demás, que el derecho de acceso de todos los ciudadanos al empleo público en condiciones de igualdad, que ahora recuerda el artículo 55 del EBEP, es un derecho fundamental proclamado en la Constitución (artículos 14 y 23.2). También es importante porque dispone que los principios de igualdad, mérito y capacidad son aplicables tanto a la selección de personal funcionario como laboral fijo o temporal, no debe olvidarse que el artículo 55.2 EBEP, no distingue entre personal laboral fijo y temporal (Vivero, 2009), igualdad que no alcanza solo al acceso al empleo, sino también al desarrollo, vicisitudes y extinción de las relaciones jurídicas de empleo, ya administrativas ya laborales.

En consecuencia considero, que la argumentación que hace el Tribunal Supremo es notoriamente infundada, pues considerar que no son equiparables los empleados fijos y los temporales e indefinidos no fijos de plantilla, porque constitucional y legalmente los primeros acceden al empleo público con respeto a los principios de mérito y capacidad, al igual que los funcionarios públicos y no así los segundos, son argumentos no endebles sino notoriamente infundados, semejante razonamiento desconoce que el acceso de cualesquiera empleados públicos, con la excepción del personal eventual, está sometido a los principios de mérito y capacidad. Desde el punto de vista constitucional el derecho de acceso al empleo público en régimen laboral no admite quiebra en función del régimen temporal o fijo de la relación individual de trabajo, corroborado por la legalidad ordinaria en el vigente artículo 55.2 EBEP. Si tanto el personal laboral fijo como el temporal deben ser seleccionados a través de los principios de mérito y capacidad - artículo 55.2 EBEP — no se justifica que al personal laboral fijo se le proteja mediante la prioridad de permanencia en el ente, organismo o entidad afectados por el procedimiento de despido colectivo y no a los segundos.

Por tanto el inciso final de la Disposición Adicional 20. ${ }^{\mathrm{a}}$ incurre en vulneración del principio de igualdad contenido en el artículo $14 \mathrm{CE}$, ya que la 
formulación del artículo 14 del texto constitucional: igualdad ante la ley o en la aplicación más igualdad en la ley o en el contenido, supone que la igualdad ante la ley se dirige al aplicador del derecho, mientras que la igualdad en la ley vincula al propio legislador. Ninguna duda puede caber, el legislador está obligado a observar el principio de igualdad, dado que su inobservancia puede dar lugar a la declaración de inconstitucionalidad de la Ley. Y es que además, el principio de igualdad ante la ley, contiene un mandato al legislador de garantizar el libre acceso de los ciudadanos a los empleos públicos, no dejándole las manos libres, pues debe establecer reglas que garanticen una aplicación imparcial del derecho. Por tanto, el principio de igualdad formal ante la ley exige que esta isonomía se encuentre de antemano en la legislación (Serrano, 1985).

En este sentido, la diferencia de trato legal entre empleados del sector público y el privado se manifiesta en el contrato indefinido no fijo al servicio de las Administraciones Públicas, que constituye precisamente el medio de prevención y de reacción contra la utilización abusiva de los contratos temporales por las Administraciones Públicas, diferencia que ha sido considerada como perfectamente acomodada al ordenamiento comunitario, en particular, a la la Directiva 1999/70/CE del Consejo, de 28 de junio de 1999, relativa al Acuerdo Marco de la CES, la UNICE y el CEPP, habida cuenta esta disposición supranacional deja cierto margen de actuación a los diferentes Estados miembros a fin de transponer sus objetivos (Fernández, 2009). De la STJCE de 7 de septiembre de 2006, tras establecer, previamente, que dicha directiva es aplicable en el ámbito o sector público, se desprende que los Estados tienen la obligación de prever abusos en la utilización sucesiva del contratos temporales del sector público, si bien no tienen la imposición de transformar los contratos temporales que traspasan los límites nacionales en indefinido ni de tratar a estos efectos, de la misma manera, los sectores privado y público.

Si bien, acto seguido exige que una previsión en tal sentido ha de venir acompañada de medidas efectivas para prevenir y sancionar semejantes irregularidades en cumplimiento de cuanto disponen la Directiva 1999/70. De una parte, por la diferencia de trato a un trabajador fijo de inicio con respecto a un trabajador indefinido no fijo cláusula 4) Principio de no discriminación; y, de otra parte, por falta de reparación de los perjuicios sufridos por el trabajador debido al uso abusivo de la Administración Pública de sucesivos contratos o relaciones laborales de duración determinada cláusula 5: (Medidas destinadas a evitar la utilización abusiva de contratos sucesivos o relaciones laborales de duración determinada).

Semejantes remedios habrán de ser ordenados por la legislación de cada Estado en correspondencia con su autonomía, que no deben sin embargo, ser menos favorables que las aplicables a situaciones similares de carácter interno (prin- 
cipio de equivalencia) ni hacer imposible en la práctica o excesivamente difícil el ejercicio de los derechos conferidos por el ordenamiento comunitario (principio de efectividad).

$\mathrm{Al}$ albur de la interpretación realizada por el órgano judicial supranacional, el ordenamiento español queda avocado a establecer algún tipo de indemnización en los supuestos de extinción del contrato indefinido no fijo consecuencia de la cobertura definitiva de la vacante o la amortización de forma reglamentaria hasta ese momento ocupada de manera irregular, pues de lo contrario la ausencia de una reparación económica «no parece superar el doble test de equivalencia y efectividad propuesto por el tribunal europeo».

Para solventar semejante contravención cabe señalar dos alternativas:

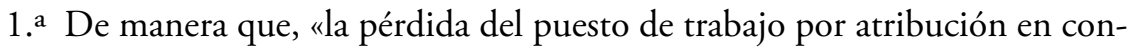
curso de méritos de la plaza ocupada a otro trabajador no es una causa consignada en el contrato sino una causa consignada en la Ley» y como tal no se podría " forzar la vía del artículo 49.1.b) ET, prevista para los pactos extintivos (o, con otra denominación, condiciones resolutorias) lícitos o no abusivos incluidos en el contenido del contrato de trabajo por voluntad de las partes», como una mejor solución, que ya anticipaba el voto particular a la STS 27/5/2002 (RCUD: 2591/2001), al señalar que «... a la hora del cese del trabajador de una Administración Pública por adjudicación a otro trabajador en concurso de méritos de la plaza que ocupaba,... la causa relacionada debe ser la extinción "por causas objetivas legalmente procedentes" (art. 49.1.l. ET),... la inclusión del cese del trabajador en la presente controversia dentro del despido procedente por causas objetivas previsto en el art. 49.1.l. del ET, definido en el art. 52.c. de la misma Ley, y regulado en el art. 53 del propio cuerpo legal no plantea inconveniente alguno en este terreno de la dogmática o sistematización de los conceptos jurídicos. ...». Y que mantiene Alarcón Caracuel, pues, en el caso del indefinido no fijo, la cobertura reglamentaria de la plaza (tras su creación formal y su inclusión en la RPT que, a veces, se dilata muchos años) no es un término, pues no se trata de un contrato temporal, sino una causa objetiva de extinción de un contrato indefinido (que no existe para los contratos fijos por razones obvias), que está fundada en el artículo 49.1,1) y regulada por los artículos 51 a 53 ET (procedimiento formal e indemnización de 20 días por año de servicio) por lo cual dicha extinción no debería ser - -aunque venía siendo- ni automática ni gratuita. (Alarcón, 2015).

2. a Más claro, si cabe, es todavía en la amortización de un puesto de trabajo dentro de la Administración, y considerar la situación dentro del marco de actuación de los artículos 49.1.1), 51 y 52 ET, concurriendo una causa de despido objetivo, que puede ser utilizada perfectamente 
cuando existan razones organizativas o de ordenación eficaz del personal que así lo justifican, y por, consiguiente, también procedería la indemnización prevista para dicho supuesto en el artículo 53.1.b) del propio Texto estatutario, que es la solución definitivamente adoptada por las STS24/6/2014 (RC 217/2013), cuya doctrina es reiterada por las SSTS (Social) 14/7/2014 (RCUD. 1807/2013 y 2052/2013).

\section{Bibliografía}

Alarcón Caracuel, Manuel Ramón, «Los despidos objetivos en el sector público. El caso particular de los trabajadores indefinidos no fijos». En Vulnerabilidad de los derechos laborales y de protección social de los trabajadores, Coord.: Rojo Torrecilla, Eduardo, Editorial Huygens, Barcelona, 2015.


sidad Complutense Madrid, Madrid, 1993.

Alonso Olea, Manuel y Casas Baamonde; M. ${ }^{a}$ Emilia, Derecho al Trabajo, Editorial Civita, Madrid, 2005.

Baylos Grau, Antonio, "Derecho al trabajo, despido y buena fe contractual (Comentarios a la STC 192/2003, de 27 de Octubre), Relaciones Laborales, núm.12, La ley $1323 / 2004$.

FERnÁNDEZ Fernández, Roberto, «La figura del contrato indefinido en la Administración: la convalidación de una mala praxis de los poderes públicos», El Estatuto Básico del Empleado Público Vol. 1, Editorial Ministerio de Trabajo e Inmigración, Madrid, 2009.

López Gandía, Juan, «La contratación temporal» en Compendio de Derecho del Trabajo. TomoII. Contrato Individual, por Albiol Montesinos, Ignacio y otros, Editorial Tirant Lo Blanc, Valencia, 2010.

López Gómez, La relación laboral especial de empleo público, Editorial Civitas, Madrid, 2009.

Mateu Carruana, María José. El contrato de interinidad, Editorial Atelier, Barcelona, 2005.

Molina Navarrete, Cristóbal. «Reforma laboral y amortización de la plaza del indefinido no fijo: ¿«cesantía» o "despido objetivo»?». Revista Doctrinal Aranzadi Social núms.9 y 10/2014, Pamplona. 2014. BIB.

Nicolás Bernad, José Alberto. Problemas Actuales del Trabajo Eventual e Interino, Editorial Lex Nova, Valladolid, 2002.

Nicolás Bernad, José Alberto «La reparación de los principios constitucionales vulnerados en la relación laboral indefinida no fija», El Estatuto Básico del Empleado Público, Vol.I, Ed. Ministerio de Trabajo e Inmigración, Madrid, 2009.

Sánchez Morón, Derecho de Función Pública, Editorial Tecnos, Madrid, 2011.

Selma Penalva, Alejandra, "El trabajador indefinido no fijo en la Administración Pública. Cuestiones controvertidas y problemas prácticos suscitados en torno a esta figura», Relaciones Laborales, núm. 11, Noviembre 2014, Año 30, tomo 1, Editorial LA LEY, LA LEY 7708/2014. 
Ramos Moragues, Francisco, "Los principios rectores de acceso al empleo público» El Estatuto Básico del Empleado Público Vol. 1, Editorial Ministerio de Trabajo e Inmigración, Madrid, 2009.

Rivero Lamas, Juan, «La garantía de los Derechos y Libertades Constitucionales», en Comentario a la Constitución Socio-Económica de España, Dirección: José Luis Monero Pérez, Ed. Comares, Granda, 2002.

Serrano González, Antonio, "El principio de igualdad ante la ley en la Jurisprudencia del Tribunal Constitucional» en De la Jurisprudencia del Tribunal Constitucional, Director: Martín-Retortillo Baquer, Editorial Institución «Fernando el Católico», Zaragoza, 1985.

Vela DíAz, Raquel «Una rectificación jurisprudencial esperada: el despido en los interinos por vacante del sector público". .Comentario a la Sentencia del Tribunal Supremo, Sala 4. ${ }^{\text {a }}$, de 24 de junio de 2014 —rec. núm. 217/2013- Revista Trabajo Seguridad Social. CEF, núm. 380, Noviembre, 2014. pp. 186-187.

Vivero Serrano, Juan Bautista, «El despido improcedente de los empleados públicos en el Estatuto Básico del Empleado Público", Revista de Derecho Social, núm. 40, 2007.

Vivero Serrano, Juan Bautista, El acceso al Empleo Público en Régimen Laboral, Editorial Tirant lo Blanch, Valencia, 2009.

Vivero Serrano, Juan Bautista, «La readmisión de los empleados públicos objeto de despido ilícito: el juego del derecho constitucional de igualdad, del artículo 96.2 EBEP y de la autonomía colectiva», Relaciones Laborales, núm. 7, Editorial La Ley, JulioAgosto 2013. 